\title{
Assessment of Fatty Acid Content in Various Brands of Imported Oils in Ethiopia by Gas Chromatography
}

\author{
Zewdu Gedefaw ${ }^{1}$, Menakath Menon $^{2}$, Estifanos Ele $^{3}$, Solomon Genet ${ }^{2,}$, \\ ${ }^{1}$ Department of Biomedical Sciences, Assosa University, Assosa, Ethiopia \\ ${ }^{2}$ Department of Biochemistry, Addis Ababa University, Addis Ababa, Ethiopia \\ ${ }^{3}$ Department of Chemistry, Addis Ababa University, Addis Ababa, Ethiopia
}

\section{Email address:}

zewdugedefaw@gmail.com (Z. Gedefaw),menakathmenon@gmail.com (M. Menon), estifanos.ele@aau.edu.et (E. Ele), solgen73@yahoo.com (S. Genet)

${ }^{*}$ Corresponding author

\section{To cite this article:}

Zewdu Gedefaw, Menakath Menon, Estifanos Ele, Solomon Genet. Assessment of Fatty Acid Content in Various Brands of Imported Oils in Ethiopia by Gas Chromatography. International Journal of Biochemistry, Biophysics \& Molecular Biology. Vol. 6, No. 1, 2021, pp. 18-25. doi: 10.11648/j.ijbbmb.20210601.15

Received: October 21, 2020; Accepted: November 9, 2020; Published: April 23, 2021

\begin{abstract}
Edible oil is a vital component of our diet. It is composed of different types of fatty acids. The type and proportion of fatty acid in oil determines the nutritional value, physical and chemical properties of edible oil and is also implicated in its quality for consumption. The main objective of this study was to assess and evaluate the fatty acid content and their type in imported edible oils widely consumed in Ethiopia. Five edible oils were analyzed for their fatty acid composition by Gas chromatography coupled with mass spectrometric detector (GC-MS). Fatty acid profile was determined after fatty acids were transformed to their corresponding fatty acid methyl esters (FAMEs). The result of this study showed that Chief palm oil, Hayat palm oil and Mona palm oil contain the highest percentage of total saturated fatty acids, 69.97\%, 53.53\%, and 50.11\% respectively. Palmitic acid and stearic acid were the predominant saturated fatty acids in these oils. Among the evaluated oils, the highest content of unsaturated fatty acids were determined in sunflower oil $(84.41 \%)$, and soybean oil $(79.55 \%)$ with the predominant presence of linoleic acid and oleic acid, compared to total unsaturated fatty acid in Mona palm oil (48.89\%), Hayat palm oil (46.29\%) and Chief palm oil (28.53\%). The fatty acid composition of soybean oil contains a healthy mixture or proportion of all the types of saturated and unsaturated fatty acids. In addition it contains balanced proportion of omega- 6 to omega-3 fatty acid and P/S index value greater than one. Therefore, soybean oil presented the healthiest fatty acid profile followed by sunflower oil and Mona palm oil, while Chief palm oil presented the least healthy fatty acid profile.
\end{abstract}

Keywords: Edible Oil, Fatty Acids, Gas Chromatography, Cardiovascular Risk, Ethiopia

\section{Introduction}

Lipids are a family of biochemical molecules that are stored in plants and animals. Lipids include fats, oils, cholesterol, waxes and others. Fats are lipids which are solid at room temperature, where as oils are liquid at room temperature. Fat and oil provide our bodies with energy. Although we can get energy from other nutrients in our diet, we need some fat and oil as they provide essential fatty acids that our bodies cannot make. Fats and oils are also carrier of the fat-soluble vitamins and involved in their absorption.

Vegetable oils are naturally occurring esters, mainly composed of triacylglycerols (TAG), which are about (95 $98 \%$ ) and variety of minor components [1]. Fatty acids constituting triglycerides are classified as saturated and unsaturated. Among unsaturated fatty acids linolenic and linoleic acid are essential, which are not synthesized endogenously and must be supplied in the diet. Partially hydrogenated vegetable oils become solid at room temperature [2-4]. Soybean, canola, palm, cottonseed, olive, coconut, peanut, sunflower, corn, palm kernel, safflower and blended oil are mostly used for food preparation around the world.

The type and proportion of fatty acid in oil determines the nutritional value, physical and chemical properties of edible oil and even implicated in its quality and applicability for 
consumption. Thus it is essential to know fatty acid content and type of oils to identify their properties and to determine the possible adulteration, as well as to know their stability [3] Evidences from studies revealed that characterizing the fatty acid composition and type in edible oils and setting recommended daily intake will reduce the risk factors of cardiovascular diseases (CVD). This is because fatty acid content of edible oil influences blood lipid profile of the consumers. Edible oils rich in unsaturated fatty acids are recommended currently because they increase concentration of high density lipoprotein (HDL) and decrease low density lipoproteins (LDL). Despite this, unsaturated fatty acids are highly prone to oxidation due to their instability. Oils rich in saturated fatty acids are stable chemically but reported to increase the concentration of low density lipoprotein (LDL). High level of LDL triggers the development of atherosclerosis, which can trigger cardiovascular complications [5].

Several published sources documented the negative effect of trans and saturated fatty acids available in oils in the development of atherosclerosis and CVD. On the other hand, essential fatty acids in oils play significant role in reducing the risk of various diseases like CVD, cancer, osteoporosis, and diabetes [4]. Therefore, proper dietary intake giving special attention to what type of fatty acid composes fats and oils could be a therapeutic option in prevention and treatment of many diseases. A recent comparative study indicated that rats fed with high cholesterol and $12 \%$ olive oil diet experienced a decrease in serum LDL, VLDL and total cholesterol (TC) levels compared to those fed with high cholesterol and sunflower oil diet. This is because monounsaturated fatty acids (MUFA) rich diet has high absorption velocity in the acinar zone 1 of the liver compared to the polyunsaturated fatty acids (PUFA) rich diet [6]. On the other hand, the reduction of serum triacylglycerol (TAG) by consumption of higher MUFA diet compared to saturated fatty acids may be associated to the increased release of oleic acid by chylomicrons [7].

Even though local production of edible oil in Ethiopia is rising, it is insufficient compared to existing homeland consumer need associated with the increase in urbanization and modernization. The main produced oil in the country is Niger seed oil. But production hardly covers the demand, thus the country remains highly dependent on imports to supply its market (unpublished result). The fatty acid profile of edible oil is determined after sample derivatization to fatty acid methyl ester (which is more volatile than the original fatty acids) using gas chromatography. In Ethiopia: Ethiopian food, medicine and health control authority has not yet made any attempt to regulate the analytical content of fatty acids in edible imported oils. Palm oil is a vegetable oil produced from fruit of tropical palm tree which is mainly cultivated in south East Asia particularly in Indonesia and Malaysia. In the unrefined form palm oil is reddish brown in color, and it has a semisolid consistency at ambient temperature. Malaysia and Indonesia produce large quantity of this oil for global export [8]. Ethiopia is one of the countries that imports huge amount of metric tons of palm oil from these countries per year. For instance in the year 2014 Ethiopia imported 340,000 metric tons of palm oil.

Consumption of imported vegetable oil is continuing without knowing its composition and suitability to frying at high temperatures. However, nowadays, many consumers started questioning and complaining the use of imported vegetable oils. This research was conceived to assess and evaluate the fatty acid profile of imported edible oils largely consumed in Ethiopia. It attempts to give some insight about changes brought in the serum lipid profile as a consequence of consumption of imported oils in the Ethiopian population. Furthermore, it creates public awareness about the potential health benefits and risks of specific types of fatty acids and may provide a good input for policy makers and researchers to protect the community from taking oils that do not meet the standard for consumption.

\section{Materials and Methods}

\subsection{Study Design and Area}

Laboratory based experimental study was conducted on palm oil, soybean oil and sunflower oil samples. The experiments were conducted in the laboratory of chemistry department of Addis Ababa University and in the laboratory of Ethiopian food, medicine and health control authority.

\subsection{Reagents, Chemicals and Grade}

Dichloromethane (99.8\%, sigma-Aldrich, USA) HPLC grade, anhydrous methanol (99.8\%), anhydrous sodium sulfate (Fluka, Buchas, Switherland), potassium hydroxide, standards of decanoic acid $(>99 \%)$ and oleic acid $(>99 \%$, sigma Aldrich, USA) were used for analysis.

\subsection{Oil Types Analyzed}

Edible oil samples used for this study were three different brands of Palm oil (Hayat, Mona and Chief), Soya bean oil and sunflower oil. Five samples of edible vegetable oils imported from abroad were collected. One liter each of Soya bean and sunflower were purchased from Shoa super market found in Addis Ababa and three liter Hayat, Mona and Cheif Palm oil were purchased from a co-operative shop and these oil samples were packed in polyethylene bottle and stored in a Refrigerator. The five samples were methylated and analyzed separately.

\subsection{Derivatization or Preparation of Fatty Acid Methyl Esters (FAMEs)}

Transesterifcation of oil samples were carried out in methanol using potassium hydroxide as a base and derivatization of fatty acid was performed according to the published procedure (GSO/ISO 12966 /2011) with little modification [9].

$1 \mathrm{gm}$ of market edible oils were weighed and transferred to round bottom flask. Each sample was warmed for 10 minutes at $50^{\circ} \mathrm{C}$ using water bath. Then $6.0 \mathrm{ml}$ of $2 \%$ potassium hydroxide $(\mathrm{KOH})$ methanolic base reagent (prepared by 
dissolving $2 \mathrm{gm}$ of $\mathrm{KOH}$ in $100 \mathrm{ml}$ of methanol) was added to each sample and was placed in a heating bath and heated at $50^{\circ} \mathrm{C}$ for 60 minutes. The round bottom flasks were fitted with condensers and shaked continuously during heating process to facilitate the reaction. After heating was completed, the round bottom flasks were allowed to cool. A 2 $\mathrm{ml}$ of saturated sodium chloride solution was added to each mixture and transferred into separatory funnel followed by adding $30 \mathrm{ml}$ of hexane. The mixture was shaken vigorously and allowed to settle to form layers. The upper organic layer was separated from the aqueous layer by running out the bottom layer. The organic layer was dried over anhydrous sodium sulfate to remove trace amount of water and filtered. Each filtrate was concentrated on rotary evaporator leaving fatty acid methyl esters, and then weighed labeled and stored in refrigerator until analyzed by GC-MS.

\subsection{Analysis of Fatty Acids}

FAMEs of each oil sample were injected to GC coupled with a mass spectrometer (Agilent technologies, 7890A GCMS, USA) and Agilent automatic detector. The chromatographic conditions were set with one $\mu \mathrm{L}$ of injection volume (splitless) and injector temperature was programmed at $275^{\circ} \mathrm{C}$. Separation was achieved on HP-5MS 5\% phenyl methyl silox capillary column $(30 \mathrm{~m} \times 250 \mu \mathrm{m}$, film thickness $0.25 \mu \mathrm{m})$. An oven temperature condition was programmed as $60^{\circ} \mathrm{C}$ for initial and held for 2 min until temperature reached $280^{\circ} \mathrm{C}$. The separation program was at a rate of $10^{\circ} \mathrm{C} / \mathrm{min}$ until it reached $200^{\circ} \mathrm{C}$ and at a rate of $3^{\circ} \mathrm{C} / \mathrm{min}$ until it reached $240^{\circ} \mathrm{C}$ with zero hold time. Helium was used as carrier gas with a total flow rate of 52.665 $\mathrm{ml} / \mathrm{min}$ and a pressure of 8 psi. Conditions of mass spectrometer were a source temperature of $230^{\circ} \mathrm{C}$, scan range
40-650 m/z, and operated in positive electron impact mode with ionization energy of 70 electro volts. Chromatographic and mass spectral data were processed using the software (MS Chemstation: Agilent technologies, USA) and identification was achieved using chromatograph library.

\section{Results}

The FAMEs of the oil samples were colorless, which was obtained after the glycerol molecule was left out. FAMEs were analyzed by GC-MS and the type and quantity of fatty acids composing the oil samples were determined. The fatty acid profile was identified by comparing the retention time and mass spectrometric fragmentation pattern corresponding to the various peaks in the sample total ion chromatogram with mass spectral database library of the national institute of standards and technology (NIST). The type and quantity of saturated fatty acids found in the oil samples are summarized in Table 1. Four types of saturated fatty acids were found. Palmitic acid was the abundant saturated fatty acid in all oil samples which ranged from $7.62 \%$ to $63.85 \%$. The highest concentration was found in Chief palm oil and the lowest in sunflower oil. Except in sunflower oil, stearic acid was the second concentrated saturated fatty acid which ranged from $6.12 \%$ in Chief palm oil to $7.52 \%$ in soybean oil. Trace amount of myristic acid was detected in all palm oil samples, but not in Chief palm oil. In addition, o-veratramide, benzyl alcohol and 2-pentanamine were found in Chief and Hayat palm oil in trace amount respectively. The concentration of branched chain margaric acid found in sunflower oil was $(6.72 \%)$ but, trace amount of unusual 2-pentanamine and diphenylephrine were also foundin sunflower oil. Yet, the toxicity of these unimportant compounds has not been reported.

Table 1. Saturated fatty acid composition of various types of imported oils (\%).

\begin{tabular}{|c|c|c|c|c|c|}
\hline \multirow{2}{*}{ Type of oil } & \multicolumn{4}{|c|}{ Saturated fatty acids (\%) } & \multirow{2}{*}{ Predominant fatty acid } \\
\hline & Myristic acid (C 14) & Palmitic acid (C 16) & Margaric acid (C 17) & Stearic acid (C 18:0) & \\
\hline Chief palm & nd & 63.85 & nd & 6.12 & Palmitic acid \\
\hline Hayat palm & 0.89 & 46.04 & nd & 6.6 & Palmitic acid \\
\hline Mona palm & 0.87 & 42.17 & nd & 6.47 & Palmitic acid \\
\hline Sunflower & nd & 7.62 & 6.72 & nd & Palmitic acid \\
\hline Soyabean & nd & 12.92 & nd & 7.52 & Palmitic acid \\
\hline
\end{tabular}

nd: not detected

The type and quantity of unsaturated fatty acids found in the oil samples are summarized in Table 2. Three types of unsaturated fatty acids of $\mathrm{C}_{18}$ family were found. Oleic acid was found to be the only MUFA which ranged from $18.77 \%$ to $46.29 \%$. The highest was found in Hayat palm oil and lowest in soybean oil. Except in Hayat and Chief palm oil, linoleic acid was the most concentrated poly unsaturated fatty acid in all oil samples, ranging from $9.73 \%$ to $57.86 \%$. The highest was presented in sunflower oil, while the lowest in Mona palm oil. Linolenic acid, the other essential fatty acid, was only found in soya bean oil (5.5\%).

Table 2. Unsaturated fatty acid composition of various types of imported oils (\%).

\begin{tabular}{llllll}
\hline \multirow{2}{*}{ Unsaturated fatty acids (\%) } & Type of oils & & & & \\
\cline { 2 - 6 } & Chief/palm & Hayat/palm & Mona/palm & Sunflower & Soyabean \\
\hline Oleic acid $\left(\mathrm{C}_{18: 1}\right)$ & 28.52 & 46.29 & 40.16 & 26.55 & 18.77 \\
linoleic acid $\left(\mathrm{C}_{18: 2}\right)$ & nd & nd & 9.73 & 57.86 & 55.28 \\
Linolenic acid $\left(\mathrm{C}_{18: 3}\right)$ & nd & nd & nd & nd & 5.50 \\
\hline
\end{tabular}

nd- not detected 
Poly unsaturated to saturated fatty acid ratio or $\mathrm{P} / \mathrm{S}$ index of oil samples ranged from $0.49: 1$ to $4.04: 1$ as shown in Table 3 below. Sunflower oil presented the highest P/S index, followed by soybean oil, where as the lowest was found in Mona palm oil. Omega- 6 to omega-3 ratio was determined only for soybean oil (10.05:1).

Table 3. The content of total fatty acids (\%), the values of $P / S$ indexes and omega-6 to omega-ratio in various types of imported oils.

\begin{tabular}{|c|c|c|c|c|c|c|}
\hline Type of oil & Total saturated fatty acid (\%) & MUFA (\%) & PUFA (\%) & Total unsaturated fatty acid \% & $P / S$ index & n-6/n-3 ratio \\
\hline Chief/palm & 69.97 & 28.53 & nd & 28.53 & ud & ud \\
\hline Hayat/palm & 53.53 & 46.29 & nd & 46.9 & ud & ud \\
\hline Mona/palm & 50.11 & 40.16 & 9.73 & 49.89 & $0.19: 1$ & ud \\
\hline Sunflower & 14.34 & 26.55 & 57.86 & 84.41 & $4.04: 1$ & ud \\
\hline Soybean & 20.44 & 18.77 & 60.78 & 79.55 & 2.97:1 & $10.05: 1$ \\
\hline
\end{tabular}

MUFA- mono unsaturated fatty acid, PUFA- poly unsaturated fatty acid, P/S index- poly unsaturated to saturated fatty acid ratio, n- $6 / \mathrm{n}-3$ - omega 6 to omega 3 ratio, nd- not detected, ud- undetermined.

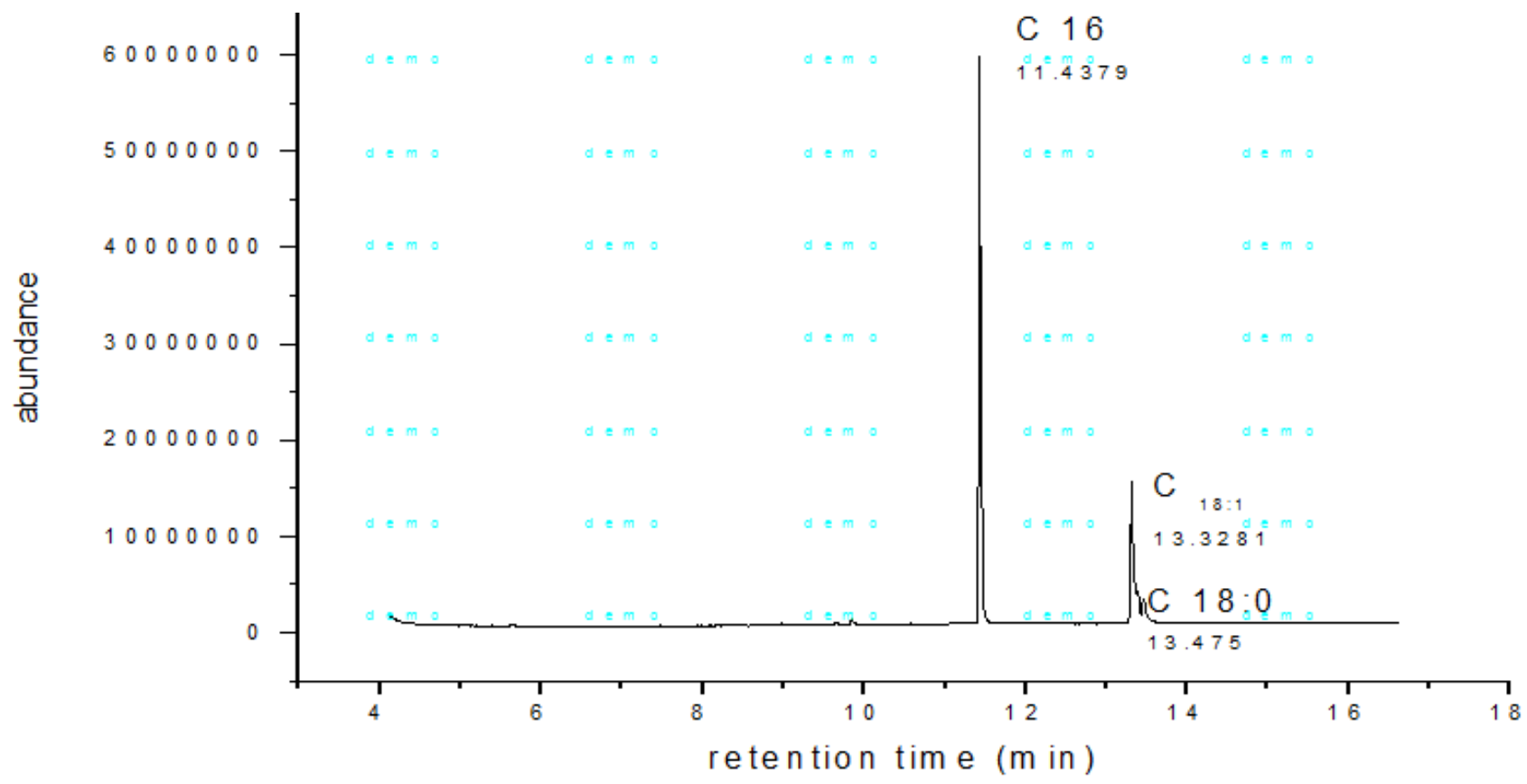

Figure 1. GC-MS Chromatogram of fatty acid methyl esters of Chief palm oil.

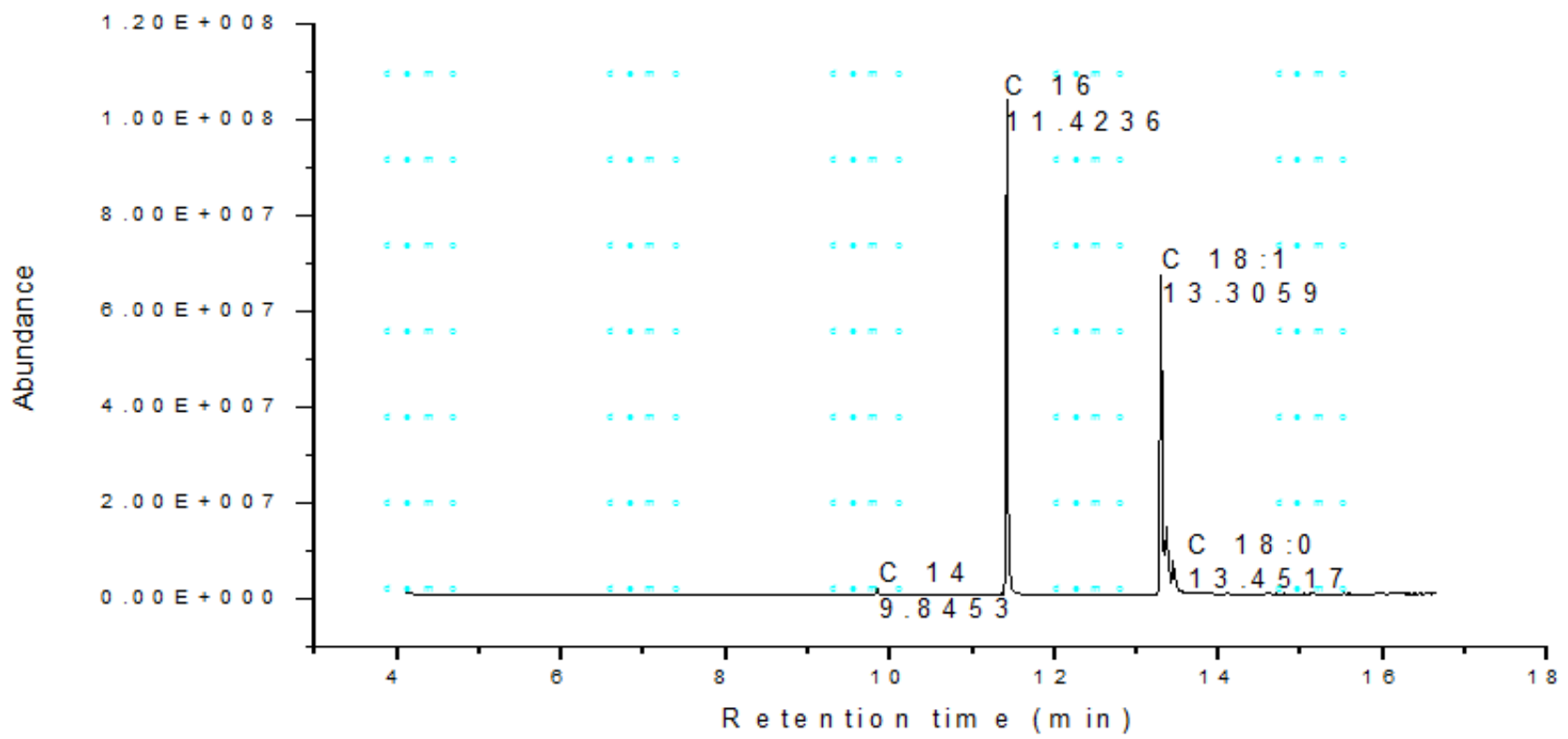

Figure 2. GC-MS Chromatogram of fatty acid methyl esters of Hayat palm oil. 


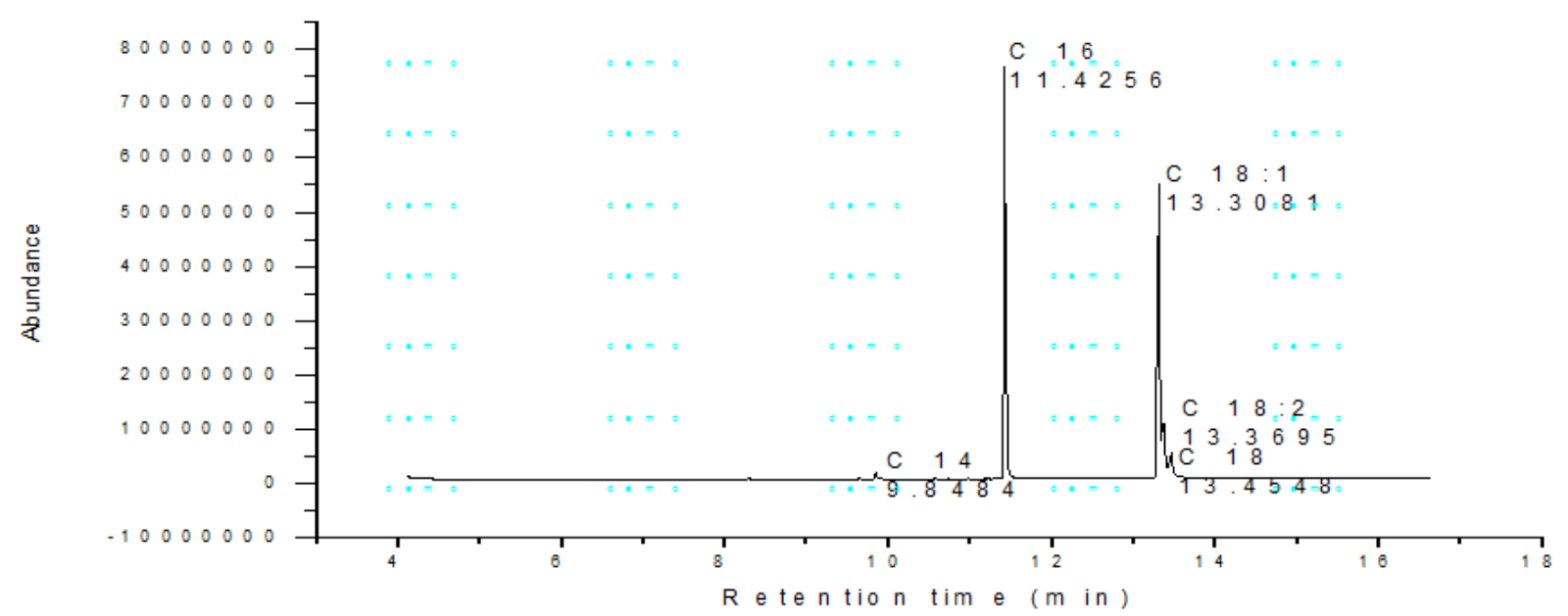

Figure 3. GC-MS Chromatogram of fatty acid methyl esters of Mona palm oil.

The GC-MS chromatographs of the fatty acid contents of the different types of edible oils are shown in Figures $1-5$.

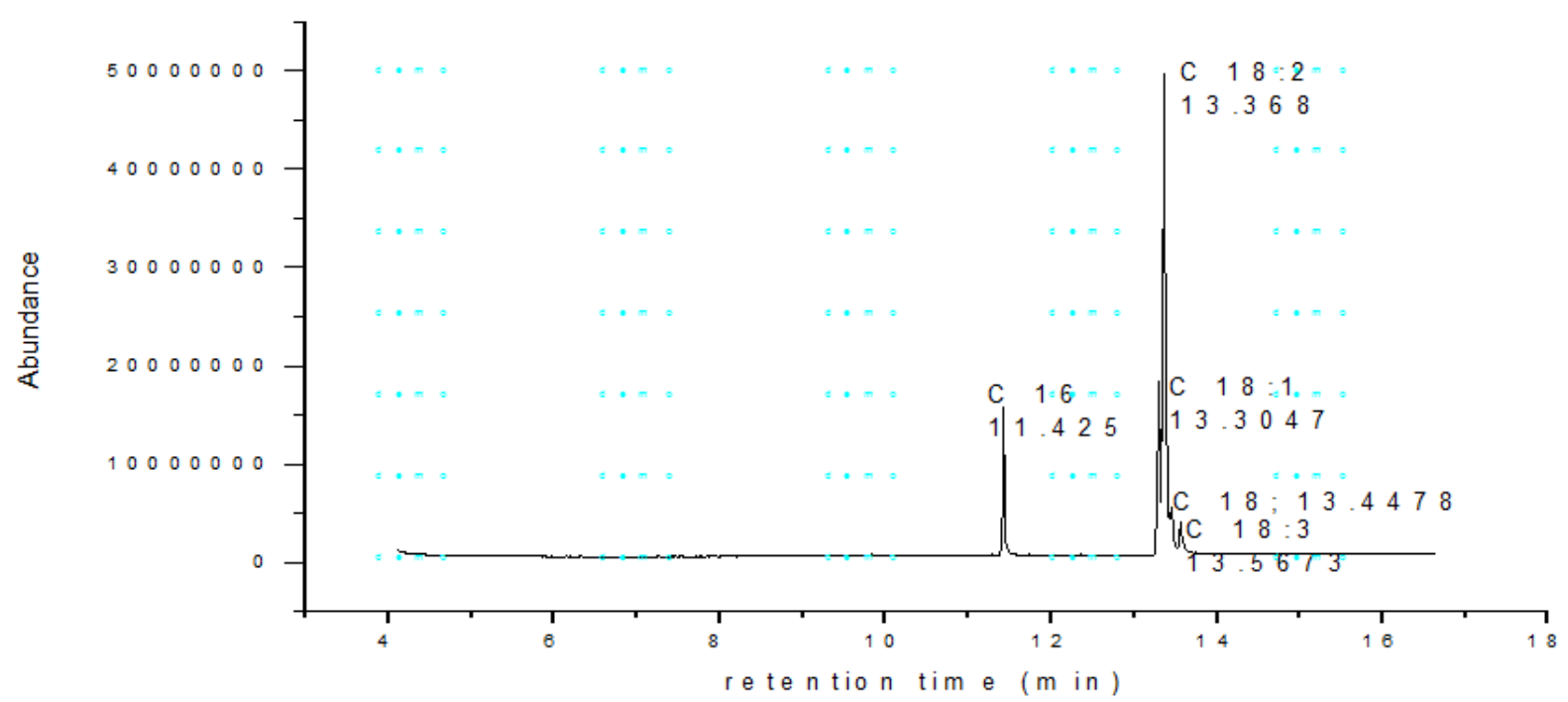

Figure 4. GC-MS Chromatogram of fatty acid methyl esters of soyabean oil.

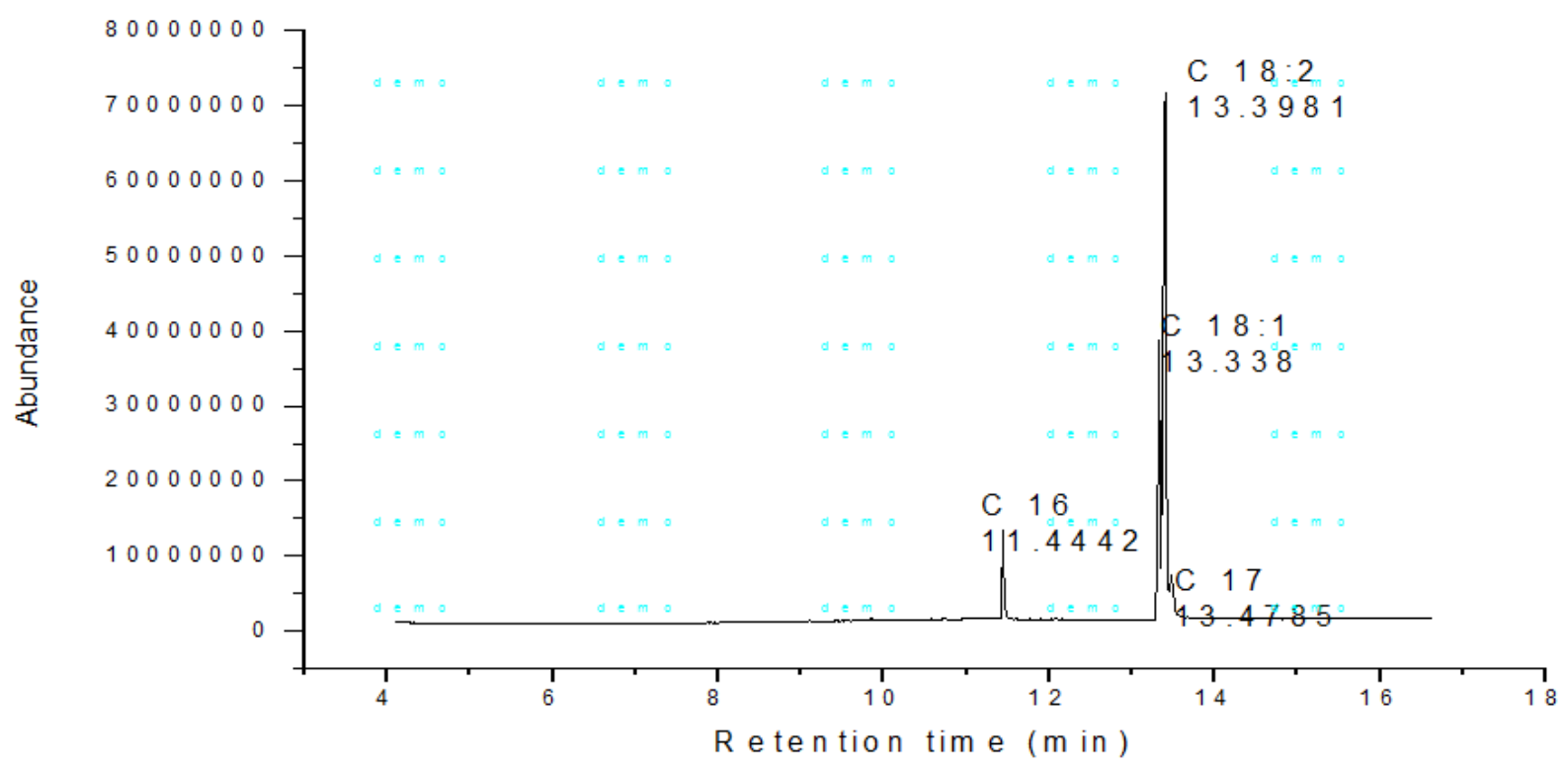

Figure 5. GC-MS Chromatogram of fatty acid methyl esters of sunflower oil. 


\section{Discussion}

The type and content of fatty acids ingested in the diet can have preventive or detrimental effect on our health. This is because dietary fatty acid composition influences serum and hepatic lipid profile, hemostatic function, oxidative stress, and inflammation, and hence knowing the content of fatty acids in our diet may be running one step in prevention and management of non communicable diseases [10]. The results of this study showed that the distribution of fatty acids in the triglyceride molecule in the evaluated oils follow the general rule. The major fatty acids present in the vegetable oil or fat showed unbranched with even number of carbon atoms, except, the presence of branched chain heptadecanoic acid in sunflower oil [11]. The level of total saturated fatty acid ranged from $14.34 \%$ for sunflower oil to $69.97 \%$ for chief palm oil, with the predominant presence of palmitic acid and stearic acid. Except sunflower and soybean oil- where total saturated fatty acids accounted below a quarter of total fatty acid (saturated and unsaturated), the othersshowed total saturated fatty acid content which is more than $50 \%$ content. Especially total saturated fatty acid in Chief palm oil accounted more than $2 / 3$ of the total fatty acid. The high saturated fatty acid content of Chief palm oil differed from other reports $[5,12]$ and also the level detected is higher than the appropriate range for total saturated fatty acid specified in the codex standard for named vegetable oils (codex standard, 2005). However, the total saturated fatty acid in Hayat palm oil and Mona palm oil was close to the results reported by other researchers $[5,13,3]$. The highest saturated fatty acid content of palm oils make them semi solid at room temperature and suitable for deep frying process and applicable for margarine and bakery [14].

Since 1960s, it has been believed that high consumption of fat increases the incidence of CVD. It is noteworthy that, not the quantity but the type of fatty acid matters, because different fatty acids have divergent effect on the risks of CVD. Consumption of high content of saturated fatty acids in the diet is linked to the risk of developing CVD and metabolic syndrome [15]. In addition, a study by Dinizet al. [16] on rat models revealed that saturated fatty acid rich-diet increases metabolic risk factors of CVD than PUFA rich-diet. However, through systematic review and meta-analysis it was concluded that consumption of high amount of saturated fatty acids is not a cardiovascular risk [17]. Another metaanalysis of prospective epidemiologic study showed that there is no significant evidence to conclude that dietary saturated fat is associated with increased risk of CVD [18]. In contrary to these studies, various studies revealed that replacement of dietary saturated fatty acids with cis MUFA and PUFA reduce the incidence of CHD or CVD [19, 20, 7]. These findings may indicate that isocaloric substitution of saturated fatty acid by unsaturated fatty acid is recommended as dietary guideline for prevention of CVD. In line with this, the Ethiopian ministry of health also recommends the use of oils rich in unsaturated fatty acids [21].
Chief palm oil presented a conspicuously high palmitic acid concentration, much higher than the reports for palm oil $[13,22]$. A study conducted in Brazil indicated that the palmitic acid content was $36.9 \%$ [23]. The higher value of palmitic acid in Chief palm oil compared to previous studies may be explained by the refining process, genetic variability, and other environmental conditions. However, the level of palmitic acid in Hayat palm oil and Mona palm oil was nearly similar to a report [3]. In addition, its level in sunflower and soybean oil was very close to the result reported by Chowdhury et al. [5]. Although, palmitic acid has been found to compose $25-30 \%$ of human adipose tissue fat [24], consumption of palmitic acid rich diet is negatively associated with coronary heart disease through increasing LDL-C and TC [25]. According to this study, it seems that sunflower oil contains more unsaturated fatty acids than soybean oil. Similarly, researchers [26, 27] reported that sunflower oil contained more unsaturated fatty acids compared to soybean oil. Oleic acid was the only concentrated MUFA found in all evaluated oil samples (Table 2). The concentration of oleic acid ranged from $18.77 \%$ to $46.29 \%$, the highest being observed in Hayat palm oil and the lowest $(18.77 \%)$ in soybean oil. The oleic acid content of Chief palm oil is below the range specified by the codex standard for oleic acid in palm oil (39.8-46\%).

Linoleic acid (omega -6) was the predominant essential fatty acid found in significant amount in sunflower oil and soybean oil. The level of linoleic acid is in the range specified by the codex standard for sunflower oil and soybean oil. A study conducted in Serbia on soybean oil indicated that the level of linoleic acids was $47.57 \pm 0.15$ [27]. From nutritional view point, the abundant presence of linoleic acid makes sunflower and soybean oil the best salad oils. Consumption of PUFA is known to play vital role in the prevention of CVD [7, 28]. In addition, intake of PUFA is inversely associated with chronic kidney disease in patients with type 2 diabetes [29]. Furthermore, PUFA intake plays key role in the prevention of atherosclerosis, coronary heart disease, cancer, type 2 diabetes, hypertension; inflammatory, thrombotic and autoimmune disease [30]. The poly unsaturated fatty acid, linolenic acid (omega -3) was found in soybean oil only. The presence of linolenic acid (5.5\%) and adequate and balanced amount of essential fatty acids make the fatty acid composition of soybean oil unique than the other evaluated oil samples. The level of linolenic acid meets the codex standard. The omega-6/omega-3 ratio is one of the important parameter that determines the nutritional value of oils. Its value in soybean oil (10.05:1) is within the ideal ratio range suggested by WHO [25]. This makes soybean oil nutritionally healthy than sunflower oil. The ratio of poly unsaturated fatty acids to saturated fatty acids $(\mathrm{P} / \mathrm{S}$ ratio) is an index of dietary fatty acid composition. $\mathrm{P} / \mathrm{S}$ index is a vital parameter for determination of nutritional value of oils. Value of $\mathrm{P} / \mathrm{S}$ index greater than one is an indicator for nutritionally healthy oil [22]. 


\section{Conclusion}

Sunflower oil followed by soybean oil had the highest content of unsaturated fatty acids. Soybean oil is unique from the rest by containing adequate amount of linolenic acid and healthy proportion or mixture of saturated and unsaturated fatty acids. Soybean oil appears superior since it contains balanced proportion of omega-6 to omega-3 fatty acid (10:1), very near to the range recommended by WHO. The higher $\mathrm{P} / \mathrm{S}$ index and total unsaturation of soybean oil and sunflower oil make them favorable as salad oil. Chief palm oil followed by Hayat palm oil and Mona palm oil showed the highest amount of total saturated fatty acids ( $>50 \%)$, which mainly accounted palmitic acid and stearic acid. The fatty acid composition of Mona palm oil is distinct than other brands of palm oil due to the presence of the essential fatty acid linoleic acid. Mona palm oil contained the healthiest fatty acid profile followed by Hayat palm oil. Chief palm oil however, presented the least healthy fatty acid profile. We would like to recommend Ethiopian food, medicine and health control authority to implement consolidated regulatory control to evaluate the quality of imported edible oil, in order to prevent consumption of unhealthy oils. In addition, further study is recommended to evaluate the trans fatty acid content of imported edible oils and identify possible adulteration and hydrogenation.

\section{Competing Interest}

The authors declare that they have no competing interest.

\section{Acknowledgements}

We highly acknowledge the Department of Chemistry, Addis Ababa University and the Ethiopian food, medicine, and health control authority, food quality assurance directorate for allowing us to use their laboratory space and equipments during analyses.

\section{References}

[1] Aluyor, EO, Ozigagu, CE, Oboh, O \&Aluyor, P. (2009) Chromatographic analysis of vegetable oils: A review. Scientific Research and Essay, 4 (4): 191-197.

[2] Strayer, D. Food fats and oil. Publication by institute of Shortening and edible oils 175 New York Avenue NW, Suite 120 Washington DC (2006). ninth edition.

[3] Zambiazi, RC, Przybylski, R, Zambiazi, MW \&Mendonca, CB. (2007) Fatty acid composition of vegetable oils and fats. B. ceppa, curitiba, 25: 111-120.

[4] Orsavova, J, Misurcova, L, Ambrozova, JV, Vicha, R \&Mlcek, J. (2015) Fatty acids composition of vegetable oils and its contribution to dietary energy intake and dependence of cardiovascular mortality on dietary intake of fatty acids. International journal of molecular sciences, 16: 12871-12890.

[5] Chowdhury, K, Banu, LA, Khan, S \& Latif, A. (2007) Studies on the fatty acid composition of edible oil. Bangladesh Journal of Scientific and Industrial Research, 42: 311-316.
[6] Duavy, SMP, Salazar, GJT, Leite, GADO., Ecker, A \& Barbosa, NV. (2017) Effect of dietary supplementation with olive and sunflower oils on lipid profile and liver histology in rats fed high cholesterol diet. Asian Pacific Journal of Tropical Medicine, 10 (6): 539-543.

[7] Dinicolantonio, JJ \& O'Keefe, JH. (2018) Effects of dietary fats on blood lipids: a review of direct comparison trials. Archives of Disease in childhood. Heart, 5: e000871.

[8] Sambanthamurthi, R, Sundram, K \& Tan, YA. (2000) Chemistry and biochemistry of palm oil. Progress in lipid research, 39: 507-558.

[9] GSO/ISO 12966/2011 Animal and vegetable fats and oils Gas chromatography of fatty acid methyl esters, Part 2: Preparation of methyl esters of fatty acids.

[10] Thijssen, MA \&Mensink, RP. (2005) Small differences in the effects of stearic acid, oleic acid, and linoleic acid on the serum lipoprotein profile of humans. The American journal of clinical nutrition, 82: 510-516.

[11] Daniewski M, Jacorzynski B, Filipek A, Balas J, Pawlizka M, and Mielniczuk E. (2003). Fatty acid content in selected edible oils. Roczniki-Panstwowego-Zakladu-Higieny 54 (3): 263-267.

[12] Ajayi, O \& Malachi, O. (2015) Comparative study of the fatty acid profiles of the vegetable oil brands consumed in Nigeria. Journal of Advances in Biology and Biotechnology, 2 (4): 200-207.

[13] Sengpracha, W, Agustin, MB, Phutdhawong, W. (2012) A survey on the fatty acid composition of commercial palm oil in Thailand. ChemSci Trans., 1 (3): 612-617.

[14] Sadoudi, R, Ahmed, DA. (2017) Studies on physico-chemical characteristics and fatty acid composition of commercially available Algerian frying edible oils. International Food Research Journal, 24 (1): 60-67.

[15] Vandijk, SJ, Feskens, EJ, Bos, M B, Hoelen, DW, Heijligenberg, R, Bromhaar, MG, Degroot, LC, De Vries, JH, Muller, M, Afman, LA. (2009) A saturated fatty acid-rich diet induces an obesitylinked proinflammatory gene expression profile in adipose tissue of subjects at risk of metabolic syndrome- . The American journal of clinical nutrition, 90: 1656-1664.

[16] Diniz, YSA, Cicogna, AC, Padovani, CR, Santana, LS, Faine, LA, Novelli EL. (2004) Diets rich in saturated and polyunsaturated fatty acids: metabolic shifting and cardiac health. Nutrition, 20 (2): 230-234.

[17] Chowdhury, R, Warnakula, S, Kunutsor, S, Crowe, F, Ward, HA, Johnson, L., Franco, OH, Butterworth, AS, Forouhi, NG, Thompson, SG. (2014) Association of dietary, circulating, and supplement fatty acids with coronary risk: a systematic review and meta-analysis. Annals of internal medicine, 160: 398-406.

[18] Siri-Tarino, PW, Sun, Q, Hu, FB, Krauss, RM. (2010) Metaanalysis of prospective cohort studies evaluating the association of saturated fat with cardiovascular disease. The American journal of clinical nutrition, 91: 535-546.

[19] Mensink, RP, WHO. (2016) Effects of saturated fatty acids on serum lipids and lipoproteins: a systematic review and regression analysis. WHO Library cataloguing data.

[20] Wang, DD, Hu, FB. (2017) Dietary Fat and Risk of Cardiovascular Disease: Recent Controversies and Advances. Annual Review of Nutrition, 37: 423-46. 
[21] Ethiopian Ministry of Health (2016) Guidelines on Clinical and Programmatic Management of Major Non Communicable Diseases in Ethiopia.

[22] Johnson, S, Saikia, N, Mathur, H, Agarwal, H. (2009) Fatty acids profile of edible oils and fats in India. Centre for Science and Environment, New Delhi, India, pp 1: 3-31. Website: http://www.cseindia.org/.

[23] Bora, PS, Rocha, RV, Narain, N, Moriera-Monteiro, A, Moriera, R. (2003) Characterization of principal nutritional components of Brazilian oil palm (Eliaesguineensis) fruits. Bioresource Technology, 87: 1-5.

[24] Kingsbury, K, Morgan, D, Heyes, T. 1964. The analysis of the fatty acids of normal human depot fat by gas-liquid chromatography. Biochemical Journal, 90: 140-144.

[25] WHO. (2003) Diet, nutrition and the prevention of chronic diseases: Report of a joint WHO/FAO expert consultation. Series 916.
[26] Kostik, V, Memeti, S and Bauer, B. (2013) Fatty acid composition of edible oils and fats. Journal of Hygienic Engineering and Design, 4: 112-116.

[27] Ivanov, DS, Levic, JD, Sredanovic, SA. 2010. Fatty acid composition of various soybean products. Food Feed Res, 37: 65-70.

[28] Lopes, LL, Peluzio, MDCG, Hermsdorff, HHM. 2016. Monounsaturated fatty acid intake and lipid metabolism. Journal Vascular Brasileiro, 15: 52-60.

[29] Dossantos, ALT., Duarte, CK, Santos, M, Zoldan, M, Almeida, JC, et al (2018) Low linolenic and linoleic acid consumption are associated with chronic kidney disease in patients with type 2 diabetes. PLoS ONE 13 (8): e0195249.

[30] Ristić-Medić, D, Vućić, V, Takić, M, Karadzić, I, Glibetić, M. (2013) Polyunsaturated fatty acids in health and diseases. Journal of the Serbian Chemical Society, 78 (9): 1269-89. 